\title{
Auditory reaction time as a function of stimulus intensity and rise time
}

\author{
J. BROWN GRIER \\ NORTHERN ILLINOIS UNIVERSITY
}

Six levels of stimulus intensity were combined factorially with six different rise times in an auditory reaction time experiment using a 1000 cps tone. Rise time had a simple effect on responses; the longer the rise time, the slower the responses. The magnitude of this effect was larger than could be accounted for by the fact that slower rising tones take longer to reach threshold. Intensity interacted with rise time so that for fast rises ( $0.5 \mathrm{msec}$.) intensity had no influence on the speed of reactions. It was only as the rate of loading the auditory system became more gradual that an intensityreaction time function was obtained.

It is well known that reaction time to the onset of an auditory stimulus depends on intensity; the more intense the stimulus, the quicker the response. For example, Woodworth \& Schlosberg (1954) present data for a typical $\mathrm{S}$ showing reaction time to decrease from about 190 msec. with a $10 \mathrm{~dB}$ tone, to only $110 \mathrm{msec}$. when a $100 \mathrm{~dB}$ tone was used. But intensity is only one of two parameters associated with the loading of a system like the ear. The rise time or rate of loading must also be considered.

From the study of certain simple mechanical and electrical systems it is known that the onset of sinusoidal stimulation produces two effects: a steady state response whose magnitude is proportional to the amplitude of the stimulus, and a transient response whose magnitude is proportional to the rate of onset of stimulation. These phenomena of simple systems occur in the auditory system also, for the amplitude of a wave is usually considered as determining loudness, while the rate of onset determines the magnitude of the transient response. This transient is the click that is heard accompanying the rapid onset of a pure tone (see Littler, 1965). But the rate of onset of a tone is simply the increase in intensity per unit of time, so that the two independent parameters of the onset of a pure tone are its amplitude and rise time.

When amplitude is manipulated it affects both the transient and steady state responses, but when rise time is manipulated it affects only the onset transients. In earlier research these onset transients were considered artifacts and several methods were suggested for their control. Woodrow (1915) and others recommended a complex tone to cover them up, and Chocholle (1941) discusses training Ss to ignore the click and respond only to the steady state tone. But the transient and steady state responses are both part of the reaction of a free system to stimulation; a more informative approach might be to study reaction time as a function of the two onset parameters.

\section{Method}

Two female college students who had participated in a previous reaction time experiment and whose auditory thresholds were known served as Ss. They were seated in a small room separate from the $E$ and all equipment. A $1000 \mathrm{cps}$ tone was presented via earphones and they were instructed to press a telegraph key as quickly as possible every time the tone came on. Six different intensity levels $(20,30,40,50,60$, and $70 \mathrm{~dB}$ above threshold) were combined factorially with six different rise times $(0.5,10,25,50,100$, and $250 \mathrm{msec}$ ). The onset of the tone was controlled by a Grason-Stadler Model 629-D electronic switch programmed so that it was on for about $5 \mathrm{sec.,}$ and then off for a similar period, so that the Ss responded about once every $10 \mathrm{sec}$.

The data collection was spread over several days at the convenience of the Ss, and short initial practice sessions were given every day. The order in which the rise times were selected were randomized, but once a period was chosen all intensities at that level were run (in a random order). Each $S$ gave 10 practice, and then 10 recorded responses in each cell of the experiment. Results

For each $\mathrm{S}$ the median of their 10 responses in each cell was determined and an analysis of variance performed on these medians. Both factors (intensity and rise time) and the interaction were statistically significant (rise time $F=165.0, d f=5 / 36, p<.001$; intensity $\mathrm{F}=22.5, \mathrm{df}=5 / 36, \mathrm{p}<.001$; interaction $\mathrm{F}=2.3, \mathrm{df}=$ $25 / 36, p<.01$ ). The average of the two medians for each cell is presented graphically in Fig. 1.

\section{Discussion}

The results indicate that both stimulus parameters associated with system loading play a role in determining the speed of reactions to a tone. The effect of rise time is straightforward; the longer the rise time, the slower the response. The intensity of the stimulus, however, has an interacting effect. As long as the rise times are relatively short, say to the order of magnitude of a half cycle or so, there seems to be little intensity effect. But as the rises become slower, intensity begins to have its well known effect on the speed of reactions. For the longer rise times (around $250 \mathrm{msec}$.) the intensity function was very pronounced.

It might be expected that rise time would have a significant effect since long rise times will delay the moment when the signal reaches threshold. But the increases observed in reaction time were much greater than can be accounted for by just this delay of onset. When the rise time was $0.5 \mathrm{msec}$. the response times averaged 183 msec.; increasing the rise time to 250 


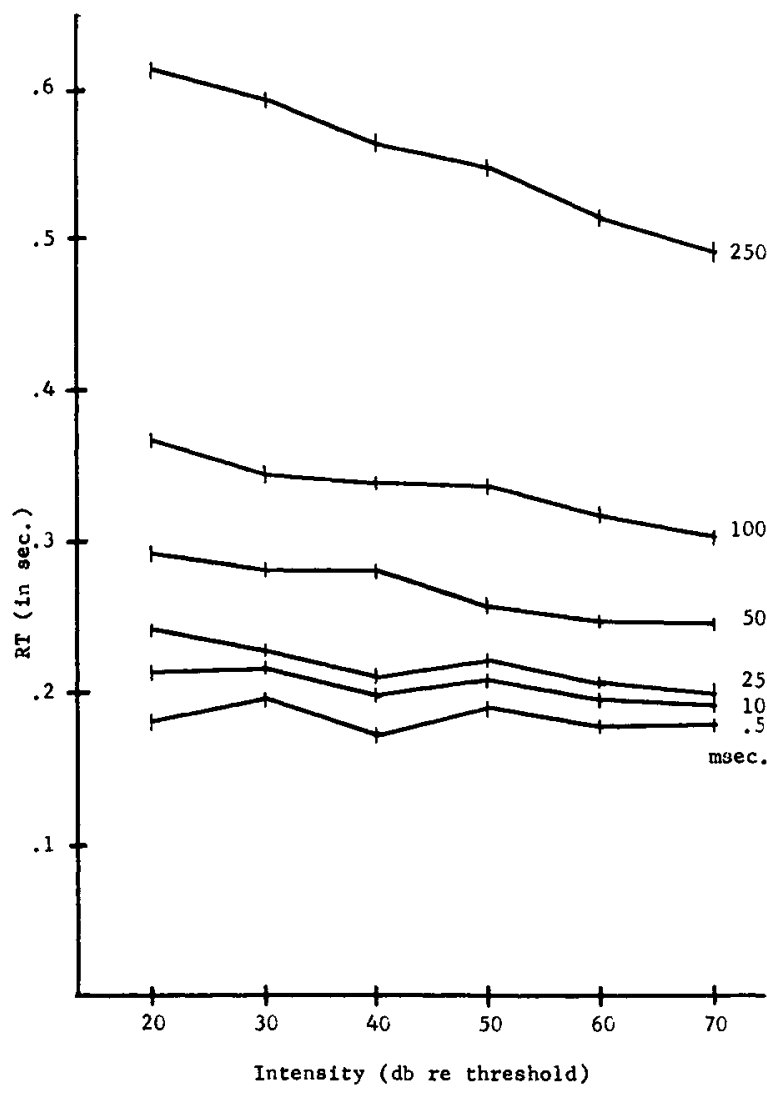

Fig. 1.

msec. then would directly add at most something less than $249.5 \mathrm{msec}$. to the response times. But in fact they were increased by an average of $369 \mathrm{msec}$. Therefore, the slowness of these responses cannot be directly accounted for by the slowness of the onset. If the ear is considered an integrating mechanism, perhaps it integrates the slower rising sounds with less efficiency.

When considered with other recent auditory research, the present study gives the following picture of the mechanisms through which stimulus intensity influences reaction time. Intensity may operate either through control of the steady state response of the ear, or through the onset transient. Both Littler (1965) and Munson (1947) have presented evidence which indicates that it takes at least $250 \mathrm{msec}$. for the auditory response of loudness to asymptote after the onset of a pure tone. If loudness is identified with the steady state response of the ear, then little information about the ultimate intensity of a sound is available through this mechanism for at least a quarter second. But many auditory reactions are completed well before a quarter second. For intensity to influence these fast responses, it likely must do so through the mechanism of the onset transients.

When the present results are compared with the classical intensity-reaction time curves of Chocholle in Woodworth \& Schlosberg (1954), two differences arise. First, the reactions in the present study are somewhat slower, perhaps due partly to the relatively long intersignal interval of $10 \mathrm{sec}$. Also, Chocholle's intensity function is almost exactly parallel to the present curve for a $50 \mathrm{msec}$. rise. This indicates that his apparatus had a rise time of $50 \mathrm{msec}$. and his Ss were faster overall because of the shorter intersignal interval. Although the rise time of Chocholle's apparatus does not seem to be reported, an examination of his methodology section leads to the suspicion that the rises were instantaneous. Further study of reactions to tones with both controlled and uncontrolled onsets is needed to settle this difference.

\section{References}

Chocholle, R. Variation des temps de reaction auditifs en fonction de l'intensite a diverse frequences, L'annee Psychol., 1941, 41-42, 65-124.

Littler, T. S. The physics of the ear. New York: The Macmillan Co., 1965.

Woodrow, H. Reactions to the cessation of stimuli and their nervous mechanisms. Psych. Rep., 1915, 22, 423-452.

Woodworth, R. S., \& Schlosberg, H. Experimental psychology. New York: Holt, Rinehart, and Winston, Inc., 1954. 